\title{
DESAIN DAN ANALISIS TEGANGAN CRANE HOOK MODEL CIRCULAR SECTION KAPASITAS 5 TON MENGGUNAKAN AUTODESK INVENTOR 2017
}

\author{
Lasinta Ari Nendra Wibawa \\ Balai Uji Teknologi dan Pengamatan Antariksa dan Atmosfer Garut \\ Lembaga Penerbangan dan Antariksa Nasional (LAPAN) \\ Email: lasinta.ari@lapan.go.id
}

\begin{abstract}
ABSTRAK
Penelitian ini mengkaji tentang perancangan dan analisis tegangan Crane Hook model Circular Section dengan kapasitas 5 ton menggunakan material Stainless Steel dan Aluminium 6061. Analisis dilakukan secara numerik dengan menggunakan software Autodesk Inventor Professional 2017. Hasil penelitian menunjukkan bahwa material Aluminium memiliki massa dan faktor keamanan yang lebih baik daripada material Stainless Steel.
\end{abstract}

Kata kunci: crane hook; autodesk inventor 2017; analisis tegangan; circular section; stainless steel; aluminium 6061 .

\begin{abstract}
This study examined the design and stress analysis of Crane Hook Circular Section models with 5 tones capacity using Stainless Steel and Aluminum 6061 materials. The analysis was carried out numerically using Autodesk Inventor Professional 2017 software. The results show that Aluminum material has more mass and safety factor better than Stainless Steel material.
\end{abstract}

Keywords: crane hook; autodesk inventor 2017; stress analysis; circular section; stainless steel; aluminium 6061

\section{PENDAHULUAN}

Kait Derek (Crane Hook) yang digunakan pada kerekan dan berbagai jenis derek memiliki peran utama dalam mengangkat beban berat di banyak sektor seperti industri alat berat, alat pengeboran minyak, dan otomotif [1]. Kait Derek dengan model circular, trapezoidal, rectangular dan triangular cross section adalah yang paling sering digunakan [2].

Kait Derek selalu mengalami kegagalan karena konsentrasi sejumlah besar tekanan yang akhirnya dapat menyebabkan kegagalannya [3]. Tegangan bending, tegangan tarik, melemahnya hook karena keausan, deformasi plastik karena beban yang berlebihan, tekanan termal yang berlebihan adalah beberapa penyebab kegagalan Kait Derek [4]. Kait Derek harus dirancang sesuai dengan kebutuhan untuk meminimalkan kegagalannya, khususnya untuk kapasitas angkat yang diinginkan. Lokasi penempatan Kait Derek juga menjadi salah satu pertimbangan penting karena sangat menentukan material apa yang akan digunakan.

Balai Uji Teknologi dan Pengamatan Antariksa dan Atmosfer atau lebih dikenal dengan nama Balai LAPAN Garut adalah sebuah balai tempat melaksanakan uji teknologi, khususnya uji statik dan uji terbang roket. Lokasi Balai LAPAN Garut yang berada di pesisir Pantai Cilauteureun membuat lingkungan Balai LAPAN Garut sangat tinggi dengan bahaya korosi [5]. Kait Derek sering digunakan untuk merakit komponen-komponen roket. Desain Kait Derek yang tahan korosi sangat diperlukan untuk menunjang tugas-tugas di Balai LAPAN Garut.

Penelitian ini menggunakan material Stainless Steel dan Aluminium 6061 yang merupakan material yang sering digunakan di tempat-tempat dengan tingkat korosi yang tinggi. Kedua material tersebut juga memiliki kekuatan luluh (yield strength) yang cukup tinggi sehingga dapat digunakan untuk mengangkat beban dengan kapasitas yang cukup besar. 


\section{METODOLOGI PENELITIAN}

Penelitian ini menggunakan perangkat lunak (software) Autodesk Inventor Professional 2017 untuk membuat gambar 3 Dimensi (3D) dan melakukan pengujian analisis tegangan dari Kait Derek dengan model Circular Section. Material yang dipilih yaitu material yang tahan terhadap ancaman korosi, yaitu Stainless Steel dan Aluminium 6061.

Autodesk Inventor merupakan perangkat pemodelan parametrik 3D. Parametrik mengacu pada penggunaan parameter desain untuk membangun dan mengendalikan model 3D yang dibuat [6]. Analisis tegangan yang dilakukan oleh Autodesk Inventor menggunakan metode analisis elemen hingga untuk memudahkan dalam menganalisis desain yang sesuai dengan keinginan kita [7]. Analisis elemen hingga adalah teknik numerik matematis untuk menghitung kekuatan dan perilaku struktur teknik dengan membagi obyek menjadi bentuk jala (mesh) [8].

Prosedur menjalankan simulasi tegangan menggunakan software Autodesk Inventor Professional 2017 ada beberapa tahapan. Pertama, mendesain rangka Kait Derek (Crane Hook) 3D. Desain meliputi bentuk, ukuran dimensi dan jenis model dari Kait Derek. Simulasi ini menggunakan desain model Circular Section. Kedua, menentukan jenis material yang digunakan. Material yang dipilih adalah Stainless Steel dan Aluminium 6061 yang keduanya merupakan material yang tahan korosi. Ketiga, menentukan batasan (constraint). Batasan yang digunakan adalah fixed constraint pada pangkal Kait Derek. Keempat, menentukan besarnya beban. Beban yang digunakan adalah 5 ton atau $49.050 \mathrm{~N}$. Kelima, menjalankan proses meshing. Proses meshing material pada simulasi ini membagi material menjadi 7294 node dan 4429 elemen. Keenam, menjalankan simulasi program. Simulasi program akan menghasilkan tegangan Von Mises, deformasi, dan safety factor. Simulasi program juga akan menampilkan titik-titik kritis dari desain yang telah dibuat.

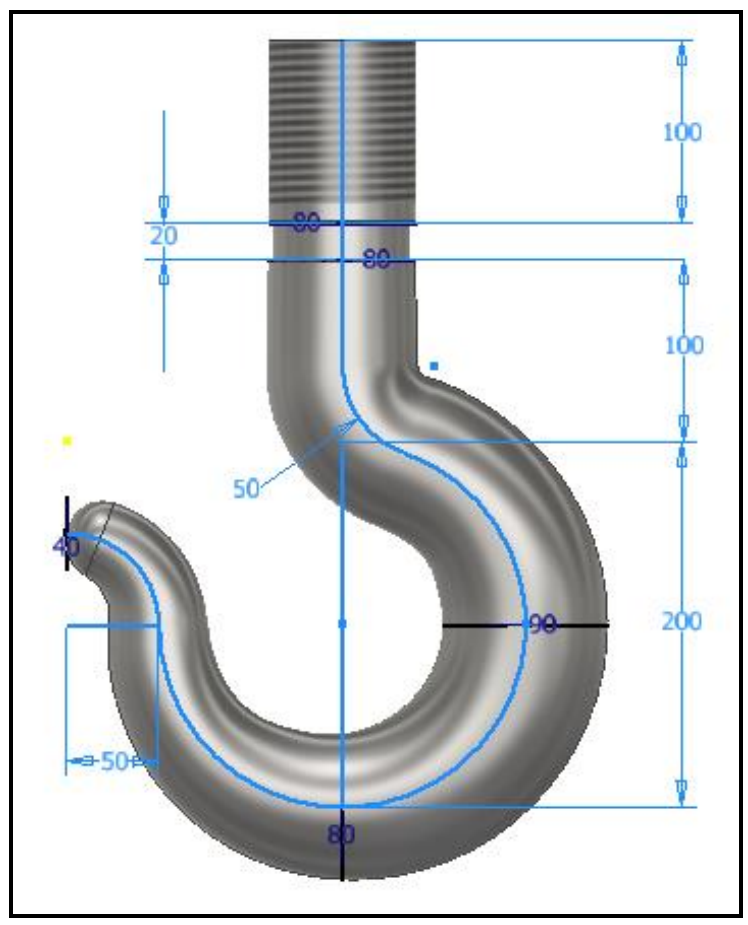

Gambar 1. Dimensi Crane Hook Kapasitas 5 Ton (dalam mm)

Parameter Analisis Tegangan menggunakan Autodesk Inventor Professional 2017 secara lengkap dapat dilihat dari Tabel 1. 
Tabel 1. Parameter analisis tegangan

\begin{tabular}{ll}
\hline Parameter & Keterangan \\
\hline Tipe Simulasi & Single Point \\
Tipe Crane hook & Circular Section \\
Kapasitas angkat maksimal & 5 Ton $(5.000 \mathrm{~kg})$ \\
Percepatan gravitasi & $9,81 \mathrm{~m} / \mathrm{s}^{2}$ \\
Total muatan & $49.050 \mathrm{~N}$ \\
Average element size & $0,1 \mathrm{~mm}$ \\
Minimum element size & $0,2 \mathrm{~mm}$ \\
Safety Factor & Berdasarkan yield strength \\
Jumlah node & 7294 \\
Jumlah elemen & 4429 \\
\hline
\end{tabular}

\section{HASIL DAN PEMBAHASAN}

\subsection{Analisis Sifat Fisik Material}

Tabel 2 menunjukkan sifat fisik material Stainless Steel dan Aluminium 6061 yang terdapat pada Autodesk Material Library. Data menunjukkan bahwa nilai ultimate tensile strength, young modulus, poisson ratio, dan shear modulus material Stainless Steel lebih unggul daripada material Aluminium 6061. Sedangkan nilai densitas dan yield strength material Aluminium lebih unggul daripada material Stainless Steel dan simulasi tegangan ini menggunakan batas nilai yield strength.

Densitas material Aluminium 6061 sebesar 2,7 gram $/ \mathrm{cm}^{3}$ atau lebih kecil daripada Stainless Steel yang mencapai $8 \mathrm{gram} / \mathrm{cm}^{3}$. Hal ini berdampak pada massa material Aluminium yang hanya sebesar 9,79 $\mathrm{kg}$, sedangkan Stainless Steel sebesar 29,01 kg. Hal ini menunjukkan bahwa material Aluminium 6061 memiliki massa yang hampir 3 (tiga) kali lebih ringan dibandingkan material Stainless Steel. Dengan kata lain, material Aluminium 6061 lebih baik daripada material Stainless Steel karena memiliki massa yang jauh lebih ringan.

Tabel 2. Perbandingan sifat fisik stainless steel dan aluminium 6061 (Autodesk Material Library)

\begin{tabular}{|c|c|c|}
\hline Material & Stainless Steel & Aluminum 6061 \\
\hline Density & $8 \mathrm{~g} / \mathrm{cm}^{3}$ & $2,7 \mathrm{~g} / \mathrm{cm}^{3}$ \\
\hline Mass & $29,01 \mathrm{~kg}$ & $9,79 \mathrm{~kg}$ \\
\hline Area & \multicolumn{2}{|c|}{$189613 \mathrm{~mm}^{2}$} \\
\hline Volume & \multicolumn{2}{|c|}{$3625840 \mathrm{~mm}^{3}$} \\
\hline Center of Gravity & \multicolumn{2}{|c|}{$\mathrm{x}=21,97 \mathrm{~mm}$} \\
\hline & \multirow{2}{*}{\multicolumn{2}{|c|}{$\begin{array}{c}\mathrm{y}=48,18 \mathrm{~mm} \\
\mathrm{z}=0,0000000016361 \mathrm{~mm}\end{array}$}} \\
\hline & & \\
\hline Yield Strength & $250 \mathrm{MPa}$ & $275 \mathrm{MPa}$ \\
\hline Ultimate Tensile Strength & $540 \mathrm{MPa}$ & $310 \mathrm{MPa}$ \\
\hline Young's Modulus & $193 \mathrm{GPa}$ & $68,9 \mathrm{GPa}$ \\
\hline Poisson's Ratio & $0,3 \mathrm{ul}$ & $0,33 \mathrm{ul}$ \\
\hline Shear Modulus & $74,23 \mathrm{GPa}$ & $25,90 \mathrm{GPa}$ \\
\hline
\end{tabular}

\subsection{Analisis Tegangan, Deformasi, dan Faktor Keamanan}

Beberapa hasil dari simulasi tegangan menggunakan Autodesk Inventor yaitu tegangan Von Mises, deformasi, dan faktor keamanan material Stainless Steel dan Aluminium 6061 terhadap pembebanan 5 Ton atau 49.050 N. Secara umum, material Stainless Steel dan Aluminium 6061 cukup aman untuk menahan beban dinamis karena nilai faktor keamanan yang dipersyaratkan material untuk menahan beban dinamis yaitu 2-3 [9]. Beban dinamis adalah beban yang dapat terjadi atau bekerja secara tiba-tiba pada suatu konstruksi. Beban dinamis umumnya kecil tetapi berubah-ubah terhadap waktu [10].

Tegangan Von Mises menjadi faktor penentu apakah material akan mengalami kegagalan atau tidak. Material dikatakan mulai luluh saat tegangan Von Mises mencapai nilai kritis yang disebut sebagai kekuatan luluh (yield strength). Kekuatan luluh adalah tegangan minimum saat material mulai kehilangan 
sifat elastisnya atau sifat material untuk kembali ke bentuk semula. Luluh akan terjadi jika tegangan desain melampaui kekuatan luluhnya.
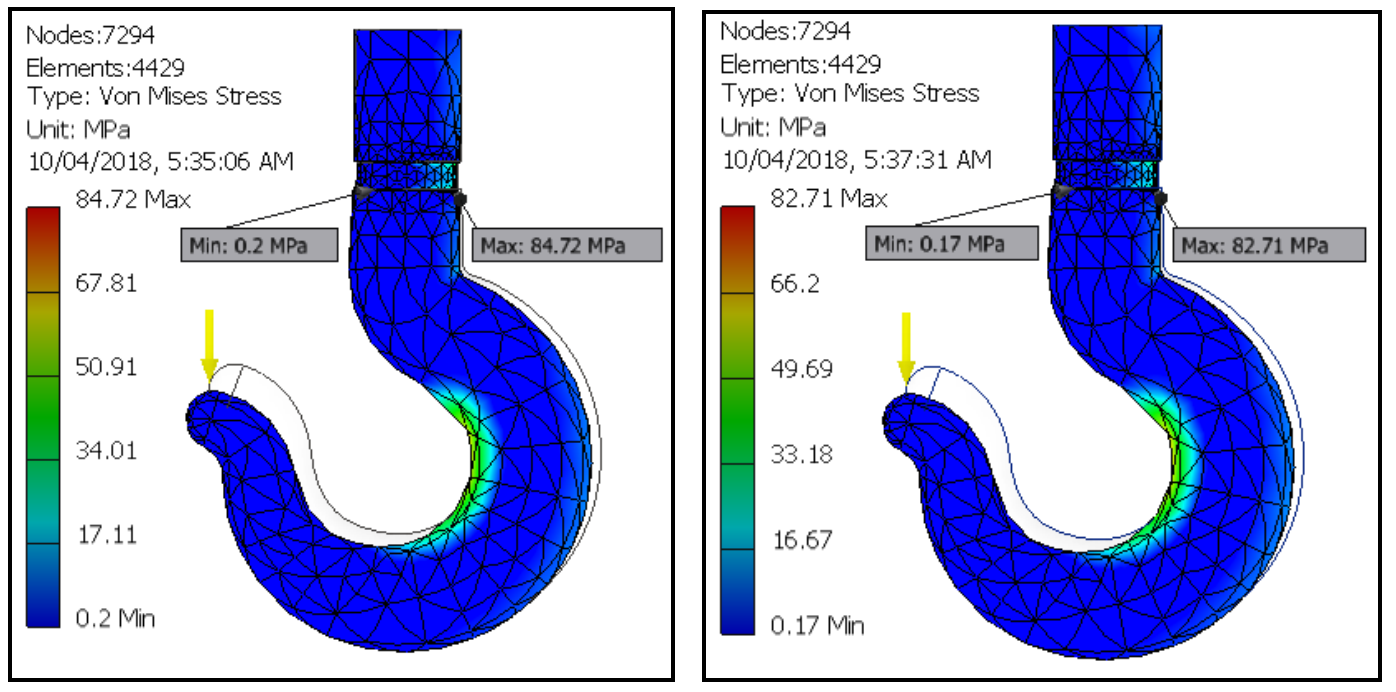

\section{Gambar 2. Tegangan Von Misses Material Stainless Steel (kiri) dan Aluminium 6061 (kanan)}

Gambar 2. menunjukkan bahwa tegangan Von Mises minimal dan maksimal material Aluminium 6061 sedikit lebih baik daripada material Stainless Steel. Tegangan Von Mises minimal dan maksimal material Aluminium 6061 sebesar 0,17 MPa dan 82,71 MPa, sedangkan Tegangan Von Mises minimal dan maksimal material Stainless Steel sebesar 0,2 MPa dan 84,72 MPa.

Deformasi merupakan salah satu indikator penting untuk menentukan apakah material yang digunakan cukup tangguh untuk menahan beban sesuai yang diinginkan. Deformasi terjadi sebagai akibat material menerima gaya atau beban. Sekecil apapun beban yang bekerja, material akan mengalami perubahan bentuk dan ukuran. Semakin rendah nilai deformasi, maka semakin kuat suatu material.

Gambar 3. menunjukkan deformasi material Stainless Steel lebih baik daripada material Aluminium 6061. Deformasi material Stainless Steel yaitu sebesar 0,2792 mm, sedangkan deformasi material Aluminium 6061 yaitu sebesar $0,7806 \mathrm{~mm}$.

Faktor keamanan (safety factor) merupakan indikator untuk memastikan apakah konstruksi yang dirancang cukup aman atau tidak untuk menahan beban. Faktor keamanan merupakan perbandingan antara tegangan ijin material dengan tegangan yang terjadi. Semakin tinggi nilai safety factor, maka semakin aman suatu konstruksi. Safety factor minimal suatu material dikatakan aman adalah 1 (satu).

Aluminium 6061 memiliki nilai safety factor yang lebih tinggi daripada material Stainless Steel (Gambar 4). Safety factor material Aluminium 6061 sebesar 3,32, sedangkan safety factor material Stainless Steel sebesar 2,95.
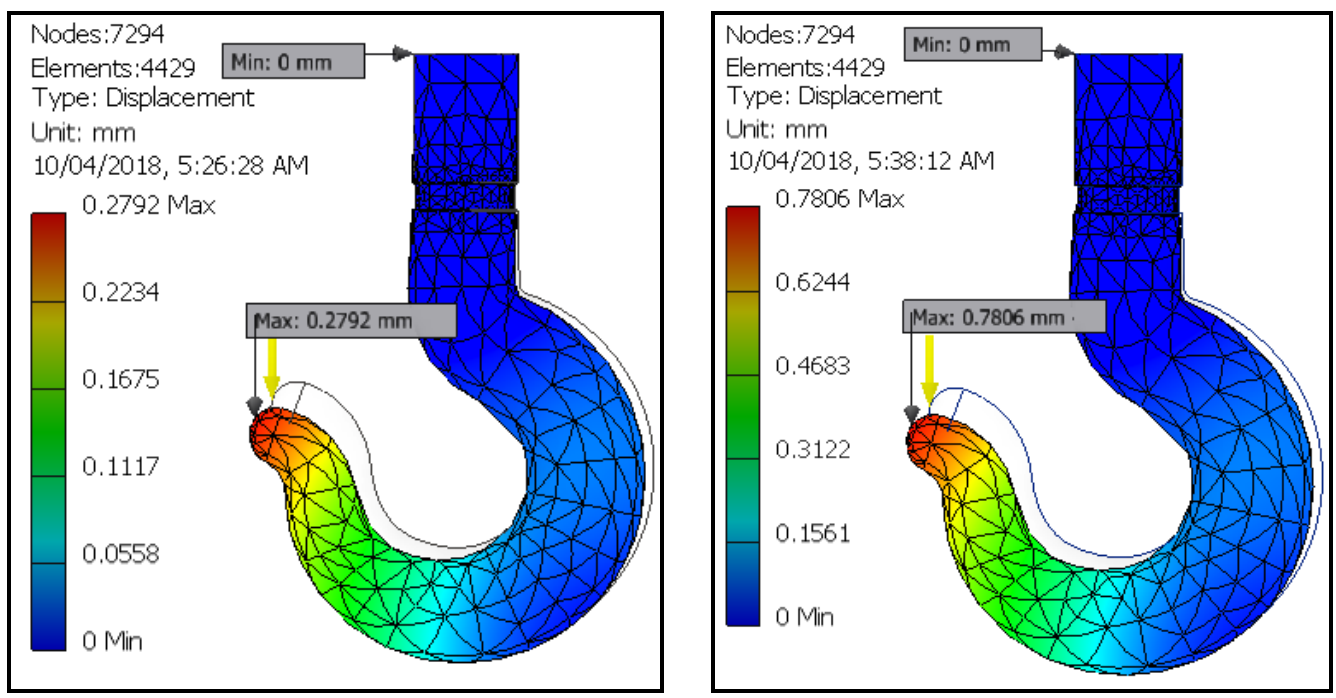

Gambar 3. Deformasi Material Stainless Steel (kiri) dan Aluminium 6061 (kanan) 

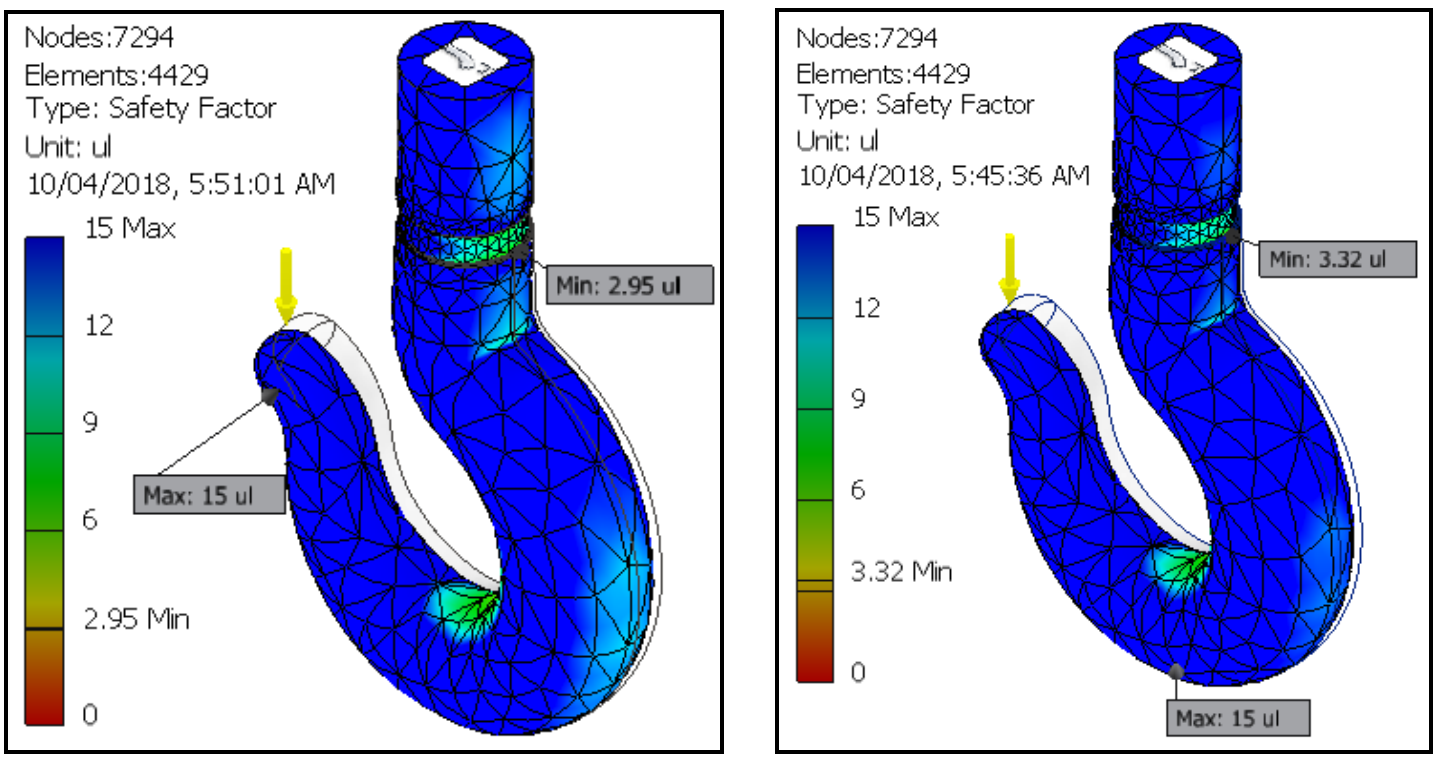

Gambar 4. Faktor Keamanan Material Stainless Steel (kiri) dan Aluminium 6061 (kanan)

\section{KESIMPULAN}

a) Desain Crane Hook menggunakan material Aluminium 6061 memiliki massa yang hampir 3 (tiga) kali lebih ringan dibandingkan material Stainless Steel. Massa material Aluminium 6061 sebesar $9,79 \mathrm{~kg}$, sedangkan Stainless Steel sebesar 29,01 kg.

b) Nilai ultimate tensile strength, young modulus, poisson ratio, dan shear modulus material Stainless Steel lebih besar daripada material Alumnium 6061. Meskipun demikian, nilai yield strength material Aluminium 6061 lebih besar daripada material Stainless Steel dan simulasi tegangan ini menggunakan batas nilai yield strength.

c) Pada pembebanan 5 Ton, material Stainless Steel memiliki nilai deformasi yang lebih rendah daripada Aluminium 6061. Deformasi material Stainless Steel sebesar 0,2792 mm, sedangkan material Aluminium 6061 sebesar 0,7806 mm.

d) Pada pembebanan 5 Ton, material Aluminium memiliki faktor keamanan lebih baik daripada Stainless Steel, yaitu sebesar 3,32. Nilai ini sangat aman saat menahan beban dinamis.

\section{DAFTAR PUSTAKA}

[1] G. Bhagyaraj, K. Suryaprakash, K. S. Rao, and C. A. D. Cam, "Crane Hook Design and Analysis," pp. 61-65, 2017.

[2] LA Joseph et al, "Structural Analysis Of Crane Hook," Int. J. Emerg. Technol. Comput. Sci. Electron., vol. 12, no. 2, pp. 108-111, 2015.

[3] E. R. Khan, V. S. Kardile, P. D. Dhakane, A. P. Gore, and B. D. Mahajan, "Design And Analysis of Crane Hook with Different Materials," Int. J. Innov. Emerg. Res. Eng., vol. 4, no. 3, pp. 227-233, 2017.

[4] M. Solanki, A. Bhatt, A. Rathour, and S. Thakkar, "Weight Optimization in Crane Hook," IJRDOJournal Mech. Civ. Eng., vol. 1, no. 6, pp. 192-196, 2015.

[5] L. A. N. Wibawa, "Desain dan Analisis Kekuatan Rangka Meja Kerja (Workbench) Balai LAPAN Garut Menggunakan Metode Elemen Hingga," J. Tek. Mesin - ITI, vol. 3, no. 1, pp. 13-17, 2019.

[6] L. A. N. Wibawa, Merancang Komponen Roket 3D dengan Autodesk Inventor Professional 2017. Buku Katta, 2018.

[7] L. A. N. Wibawa, Simulasi Kekuatan Komponen Sarana Pengujian Roket Menggunakan Autodesk Inventor Professional 2017. Buku Katta, 2018.

[8] L. A. N. Wibawa, "Desain dan Analisis Kekuatan Rangka Tempat Sampah di Balai LAPAN Garut Menggunakan Metode Elemen Hingga,” Turbul. J. Tek. Mesin, vol. 1, no. 2, pp. 64-68, 2019.

[9] V. Dobrovolsky and K. Zablonsky, Machine Elements. Peace Publisher, 1982.

[10] L. A. N. Wibawa dan D. A. Himawanto, "Analisis Ketahanan Beban Dinamis Material Turbin 
Jurnal SIMETRIS, Vol. 10 No. 1 April 2019

P-ISSN: 2252-4983, E-ISSN: 2549-3108

Angin Terhadap Kecepatan Putar Rotor (rpm) Menggunakan Metode Elemen Hingga," J. Simetris, vol. 9, no. 2, pp. 803-808, 2018. 